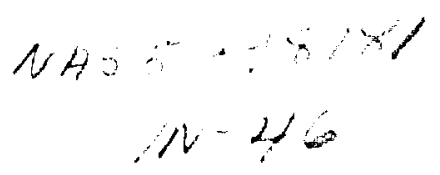

\title{
THE TROPICAL UPPER TROPOSPHERE AND LOWER STRATOSPHERE IN THE GEOS-2 GCM
}

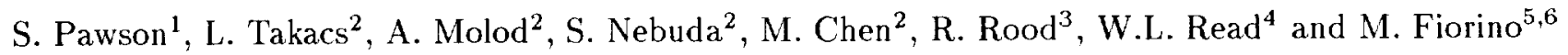 \\ 1 Universities Space Research Association, NASA GSFC, Code 916, Greenbelt, MD 20771, USA \\ ${ }^{2}$ General Sciences Corporation, NASA GSFC, Code 910.3, Greenbelt, MD 20771, USA \\ ${ }^{3}$ NASA GSFC, Code 910.3, Greenbelt, MD 20771, USA \\ 4 Jet Propulsion Laboratory, Pasadena, CA 91109, USA \\ 5 PCMDI, Lawrence Livermore National Laboratory, Livermore CA 94550, USA \\ ${ }^{6}$ Present affiliation: ERA-40 Project, ECMWF, Shinfield Park, Reading, RG2 9AX, UK
}

\section{ABSTRACT}

The structure of the tropical upper troposphere and lower stratosphere in the GEOS-2 General Circulation Model (GCM) is discussed. The emphasis of this study is on the reality of monthly-mean temperature and water vapor distributions in the model, compared to reasonable observational estimates. It is shown that although the zonal-mean temperature is in good agreement with observations, the GCM supports an excessive zonal asymmetry near the tropopause compared to the ECMWF Reanalyses. In reality there is a QBO-related variability in the zonally averaged lower stratospheric temperature which is not captured by the model. The observed upper tropospheric temperature and humidity fields show variations related to those in the sea surface temperature, which are not incorporated in the GCM; nevertheless, there is some interannual variability in the GCM, indicating a component arising from internal processes. The model is too moist in the middle troposphere $(500 \mathrm{hPa})$ but too dry in the upper troposphere, suggesting that there is too little vertical transport or too much drying in the GCM. Transport into the stratosphere shows a pronounced annual cycle, with drier air entering the tropical stratosphere when the tropopause is coldest in northern winter; while the alternating dry and moist air masses can be traced ascending through the tropical lower stratosphere, the progression of the anomalies is too rapid.

\section{INTRODUCTION}

There is an increasing recognition that stratospheric change, particularly the reponse of the ozone layer to anthropogenic activity, can impact the terrestrial climate by perturbing the radiation balance of the atmosphere. Similarly, as understanding of the different chemical and dynamical processes of the atmosphere become better understood, the complexity of their interactions and the importance of treating these in a complete physical system are becoming apparent. For these reasons, several general circulation models (GCMs) incorporating the troposphere and the middle atmosphere have been developed over the past 5-10 years. One of these is the Goddard Earth Observation System (GEOS) GCM, which can be run in climate model and forms an integral part of the troposphere-middle atmosphere data assimilation system (DAS) at NASA Goddard Space Flight Center.

This paper presents a limited validation of a free-running "climate" integration of the GEOS-2 GCM, which 
is described in the next section. The emphasis is on the tropical upper troposphere and lower stratosphere; this is a key region when the transport of trace gases from the free troposphere into the middle atmosphere is of concern. Validation of the free-running model is important because any systematic errors which appear are likely to impact upon the performance of the DAS, so an understanding of any deficiencies of the GCM should eventually help interpretation of the analyses.

\section{THE GEOS-2 GENERAL CIRCULATION MODEL}

As a component of the DAS in use at NASA GSFC, a comprehensive general circulation model (GCM) has been developed, and is under progressive modification. The current version, the GEOS-2 GCM, is a part of the GEOS-2 DAS being used in conjunction with the Tropical Rainfall Measuring Mission (TRMM) campaign; its immediate predecessor, the GEOS-1 GCM, was a component of the GEOS-1 DAS, used for the NASA Reanalysis project (Schubert $e t$ al., 1993). The GEOS-2 GCM and DAS are described by DAO (1996). Some of the most relevant aspects of the GCMs are summarized here.

One of the major differences in the operational implementation of the GEOS-1 and GEOS-2 models concerns the vertical structure. The GEOS-1 GCM and DAS had a tropospheric configuration, with 20 levels and an upper boundary in the middle stratosphere (Takacs et al., 1994; Takacs and Suarez, 1996). Some tropospheremiddle atmosphere configurations of the GEOS-1 system were employed, and several periods of atmospheric analyses are available with several different configurations of that system. The GEOS-2 GCM and DAS have routinely been implemented with 70 levels, extending up to the lower mesosphere. The configuration of the GEOS-2 GCM is thus suited to studies of the coupled troposphere-middle atmosphere system, in a model environment with a relatively high vertical resolution compared to many other current GCMs. One drawback for middle atmospheric work is that a $\sigma$ coordinate is used, which means that the surface topography affects the model levels up through the middle atmosphere.

In the horizontal, the dynamical core of the model is formulated in gridpoint space, on an Arakawa Cgrid, using fourth-order differencing and an explicit, leapfrog time-stepping scheme. The GEOS-2 GCM is normally used with a resolution of $2.5^{\circ} \times 2^{\circ}$ in longitude and latitude, but integrations with both coarser and finer resolutions are often performed. Takacs and Suarez (1996) discuss some sensitivity of the GEOS$1 \mathrm{GCM}$ to the order of discretization and the horizontal resolution. The filtering necessary to maintain computational stability in the model is described in Takacs et al. (1994).

Radiation transfer is calculated using the parametrization developed by Chou (1992) for the shortwave and Chou and Suarez (1994) for the longwave; in the current configuration, longwave radiation transfer is calculated for the major bands of the major gases $\left(\mathrm{H}_{2} \mathrm{O}, \mathrm{CO}_{2}\right.$ and $\left.\mathrm{O}_{3}\right)$ and the shortwave absorption due to the same gases, as well as $\mathrm{O}_{2}$ in the higher stratosphere and mesosphere. Cloud effects are incorporated using random and maximum overlapping models (see Takacs et al., 1994) and optical thicknesses are as described in DAO (1996).

The cloud distributions are determined using a relaxed Arakawa-Schubert scheme (Moorthi and Suarez, 1992) for penetrative and shallow convection, as well as a representation of large-scale cloudiness. Surface fluxes of moisture, heat and momentum are treated after Helfand and Schubert (1995) and a turbulence parametrization (Helfand and Labraga, 1988) is also implemented. A parametrization of topographic gravitywave drag is also employed; Takacs and Suarez (1996) demonstrated that this significantly improves the representation of total stress in the GCM, when compared to the GEOS-1 reanalyses.

The model simulation discussed in this paper was run using climatological sea-surface temperatures (Reynolds, 1988) and sea ice distributions (Gates, 1992) at the lower boundary; monthly-mean values were interpolated linearly with time in a cyclic manner. Over land, the vegetation type (DeFries and Townsend, 1994) and the soil moisture (Schemm et al., 1992) were specified; the climatological roughness lengths were also predetermined (Dorman and Sellers, 1989). Snow cover was assumed when the ground temperature over land fell below freezing. Using these climatological lower boundary conditions, the model was integrated for six years beginning in November 1991; the time is relative to this starting date, and bears no relationship with time in the "real atmosphere" because of the different boundary conditions and the limits on deter- 


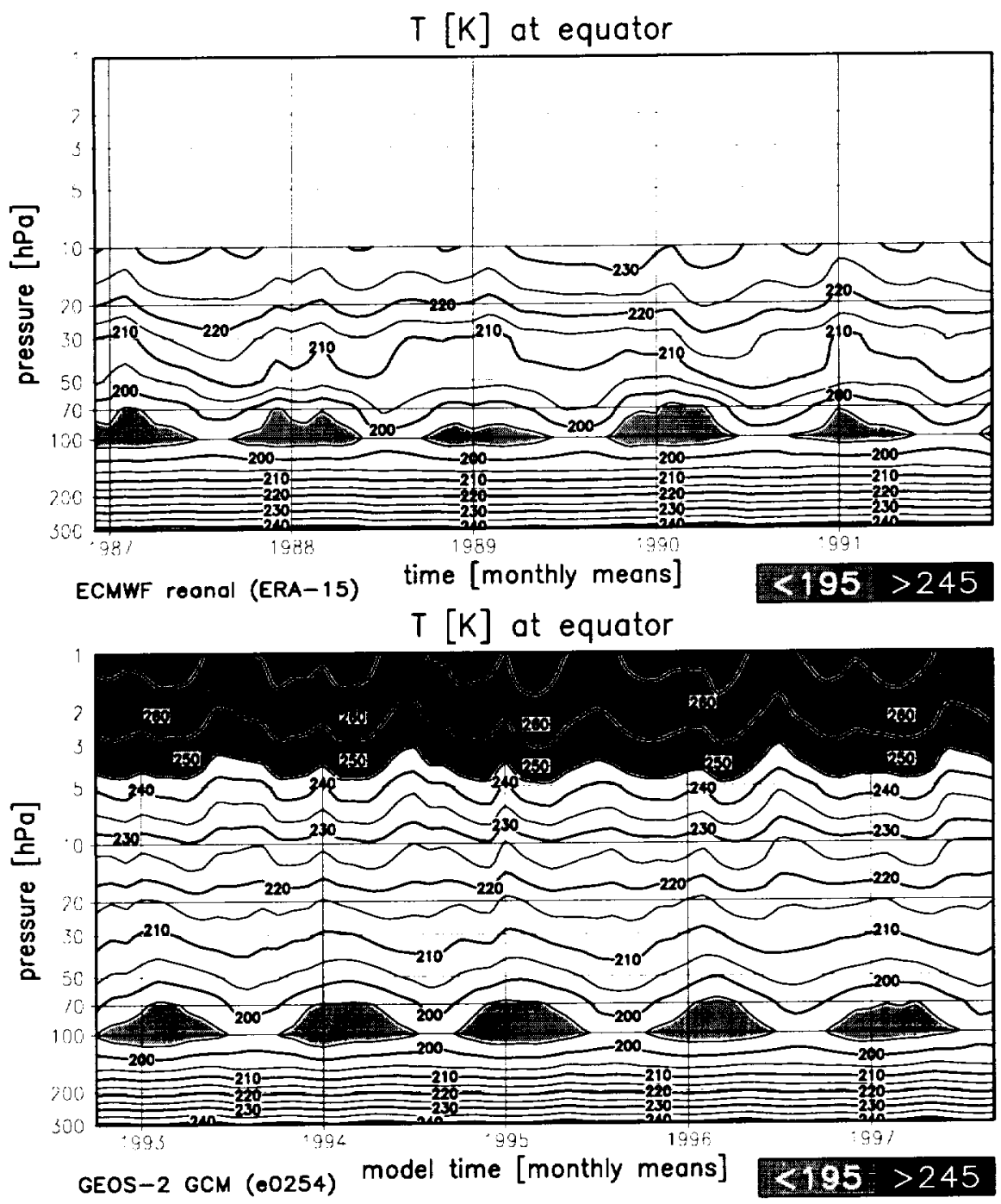

Fig. 1: Time series of the monthly-, zonal-mean temperature $(\mathrm{K})$ at the equator, between 300 and $1 \mathrm{hPa}$. The top panel shows a five-year extract from ECMWF reanalyses (Gibson et al., 1997), used as a reference, which were determined in an analysis system with an upper boundary at $10 \mathrm{hPa}$. The lower panel is from the GEOS-2 GCM simulation. The contour interval is $5 \mathrm{~K}$ and regions colder than $195 \mathrm{~K}$ are shaded.

ministic predictability.

\section{THERMAL STRUCTURE}

The first quantity to be discussed is the temperature in the tropical tropopause region. As a reference, the reanalyzed data from the European Centre for Medium Range Weather Forecasts (ECMWF) are used; Pawson and Fiorino (1998a) have demonstrated that this dataset reproduces estimates from radiosondes very well near the tropical tropopause, and much better than products which incorporate temperatures from satellite data in an inappropriate manner.

Figure 1 shows time series of the vertical temperature structure in the GEOS-2 GCM and the ECMWF reanalyses (Gibson et al., 1997). In the upper troposphere, the lapse rate from the GCM is in good agreement with the ECMWF data, and the temperature minimum near $100 \mathrm{hPa}$ is well simulated, both in its altitude and the timing of the coldest regions in the northern winter months. What is less well represented in the 

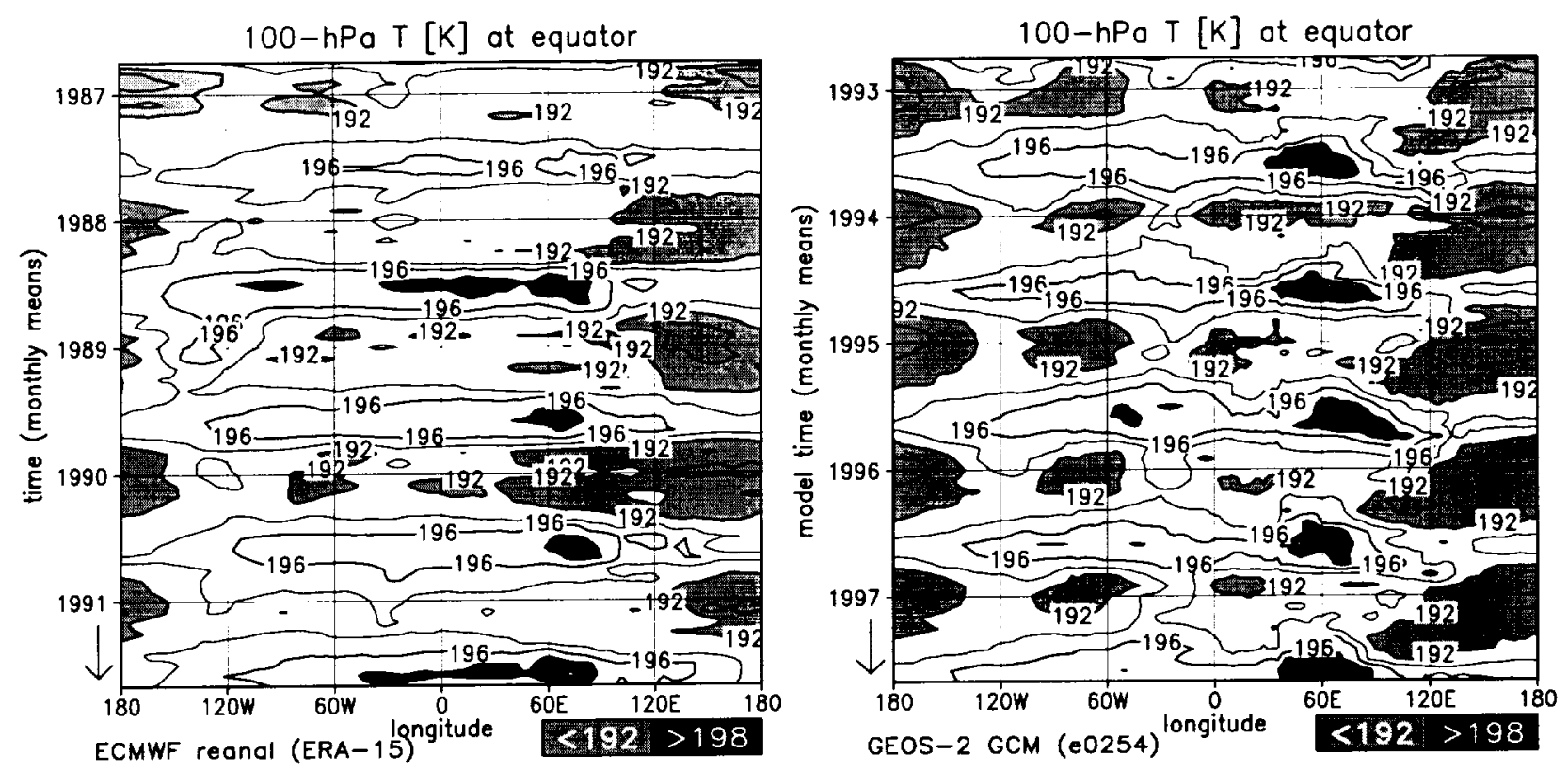

Fig. 2: Time series of the monthly averaged $100-\mathrm{hPa}$ temperature $(\mathrm{K})$ at the equator. The longitudinal structure is shown. The left-hand panel shows a five-year extract from ECMWF reanalyses (Gibson et al., 1997). The right-hand panel is from the GEOS-2 GCM simulation. The contour interval is $1 \mathrm{~K}$ and regions colder/warmer than $192 \mathrm{~K} / 198 \mathrm{~K}$ are shaded light/dark.

model simulation are the year-to-year variations in the depth of the cold region and the lower stratospheric temperatures. A large part of this variability in the real atmosphere is related to the tropical quasi-biennial oscillation, which is not captured in the GEOS-2 GCM (in common with most other current models), and which is underestimated in the ECMWF reanalyses (Pawson and Fiorino, 1998b).

Hovmöller diagrams, showing the longitude-time evolution of the monthly averaged equatorial temperature at $100 \mathrm{hPa}$ (Fig. 2), reveal the location of the colder and warmer regions in the tropics. The GEOS-2 GCM correctly captures the coldest region over the Maritime Continent, with the lowest temperatures in January; these are slightly lower than those in the ECMWF reanalyses. The second cold region near $70^{\circ} \mathrm{W}$ is too prominent in the GEOS-2 GCM, while a third region over Africa barely shows in the observational estimate. The highest upper tropospheric temperatures in both the ECMWF reanalyses and the GEOS-2 GCM appear near $60^{\circ} \mathrm{E}$, and are slightly warmer in the simulation (so that the cancellation between the warm and cold regions leads to the excellent agreement in the zonal means, Fig. 1). The interannual variability of the observed temperatures is not reproduced by the GCM, which does display some variability related to the internal processes of the model (since there is no year-to-year variation in the boundary conditions). The observed variability is related to such features as the Southern Oscillation Index (SOI), or the warmth and location of the Pacific warm pool, these "El Niño"-driven changes to the convection and the Walker circulation leading to interannual temperature differences. Notably, in August 1988 and August 1991 the warm region (with $T>198 \mathrm{~K}$ ) extended westward from India to South America, while in other years such high temperatures were not attained.

\section{WATER VAPOR}

Water vapor is an important atmospheric constituent, because of both its radiative effects (it is the strongest greenhouse gas in the troposphere) and the importance of the hydrological cycle in determining the terrestrial environment. The main source is evaporation from oceans and moist land, and the main sink is precipitation. As such, the distribution of water vapor is determined by physical processes which are parametrized in current 
general circulation models, which act to locally increase or decrease the concentration, and the transport by the resolved winds, which redistribute atmospheric moisture to regions where it may condense out and be lost to the atmosphere. The success of any simulations of the moisture content of the upper troposphere and lower stratosphere are thus highly sensitive to the accuracy of the the physical processes included in the model, to the reality of the simulated wind distributions, and to the ability of the advection scheme to transport water vapor (and liquid water, if it were to be included as a prognostic variable, which is not the case in the GEOS-2 simulation discussed here) in a physically realistic manner. One obvious point is that since the water vapor concentration decreases rapidly with increasing altitude above the planetary boundary layer, the redistribution by large-scale transport is especially sensitive to errors in the vertical transport (in either the velocities themselves or in the numerical formulation). The lack of condensational processes in the lower stratosphere means that the water vapor there is an excellent tracer of the atmospheric motions and can be used to assist the validation of models.

It is therefore of considerable interest to examine the distribution of water vapor in the GEOS-2 GCM in comparison to observations. The discussion begins in the troposphere and works it way upwards into the lower stratosphere. At $500 \mathrm{hPa}$, the GEOS-2 GCM results were compared to the GEOS-1 reanalysis; these were performed using a DAS in which the atmospheric model was represented by the GEOS-1 GCM (Schubert et al., 1993). The observational constraints on the DAS mean that the choice of GCM does not prevent validation of a new model version against a product which includes information from a previous version of the same model. In the lower and middle troposphere there are direct observational constraints on water vapor, as well as thermodynamical constraints linked to the temperature structure and the manner in which the parametrized cloud processes are activated by the assimilated data.

Hovmöller diagrams of the 500-hPa specific humidity $(q)$ at the equator (not shown) reveal that the GEOS-2 GCM captures the essential longitudinal structure of the observational estimate (the GEOS-1 DAS), but that there are some systematic discrepancies. The moist region centered on $120^{\circ}$ is too wet in the GCM, peaking about $25 \%$ higher than the analysis, and in March-April merging with the moist region over Africa; the wet air over Brazil is broader in the simulation and the peak in the late part of the year is too strong. The dry regions are all too limited in extent in the simulation. Overall, there is a wet bias to the model simulation compared to the GEOS-1 reanalyses. Note also that the GEOS-1 reanalyses are slightly drier than the ECMWF reanalyses at $500 \mathrm{hPa}$.

Moving upwards through the atmosphere, the upper tropospheric specific humidity is now discussed, comparing three different "observational" datasets near $150 \mathrm{hPa}$ with the GEOS-2 GCM (Fig. 3). The first observational dataset is from the Upper Atmosphere Research Satellite-Microwave Limb Sounder (UARSMLS) (Read et al., 1996, 1999); these upper tropospheric distributions were determined from the channel measuring near $205 \mathrm{GHz}$, which was originally included to determine middle atmospheric ClO distributions. Read et al. (1996) described the techniques used to determine the upper tropospheric content, noting that the most reliable retrievals are for the level near $12 \mathrm{~km}$ in the tropics. In the original dataset (Read et al. 1996) there was a moist bias at $147 \mathrm{hPa}$, but subsequent reprocessing has reduced this bias when compared to UARS-Halogen Occultation Experiment (UARS-HALOE) and Stratospheric Aerosol and Gas Experiment (SAGE) estimates of the same quantity (Read et al., 1999). Note also that the UARS-HALOE and SAGE estimates should be conservative, because the measurement technique is affected by the presence of upper tropospheric cirrus cloud, preventing estimates of the moisture in those regions; as a microwave sampler, the UARS-MLS can provide useful information in these moister parts of the upper troposphere. Sandor et al. (1998) present further estimates of this drier upper troposphere in the Version 4 MLS data, which were also used here.

Despite the reduced estimate of upper tropospheric moisture in the later processed versions of the dataset, there is a moist bias when the data are compared to ECMWF Reanalyses; the upper two panels of Fig. 3 look qualitatively very similar, with coincident wet and dry bands, but the contour interval and shading in the MLS data are twice as large as those for the ECMWF Reanalyses. The GEOS-1 DAS (Schubert et al., 1993) gives specific humidities about four times larger than the ECMWF system (Gibson et al., 1997), with minima in the arid regions of slightly less than $24 \mathrm{mg} / \mathrm{kg}$ and maxima exceeding $40 \mathrm{mg} / \mathrm{kg}$. In the GEOS-1 

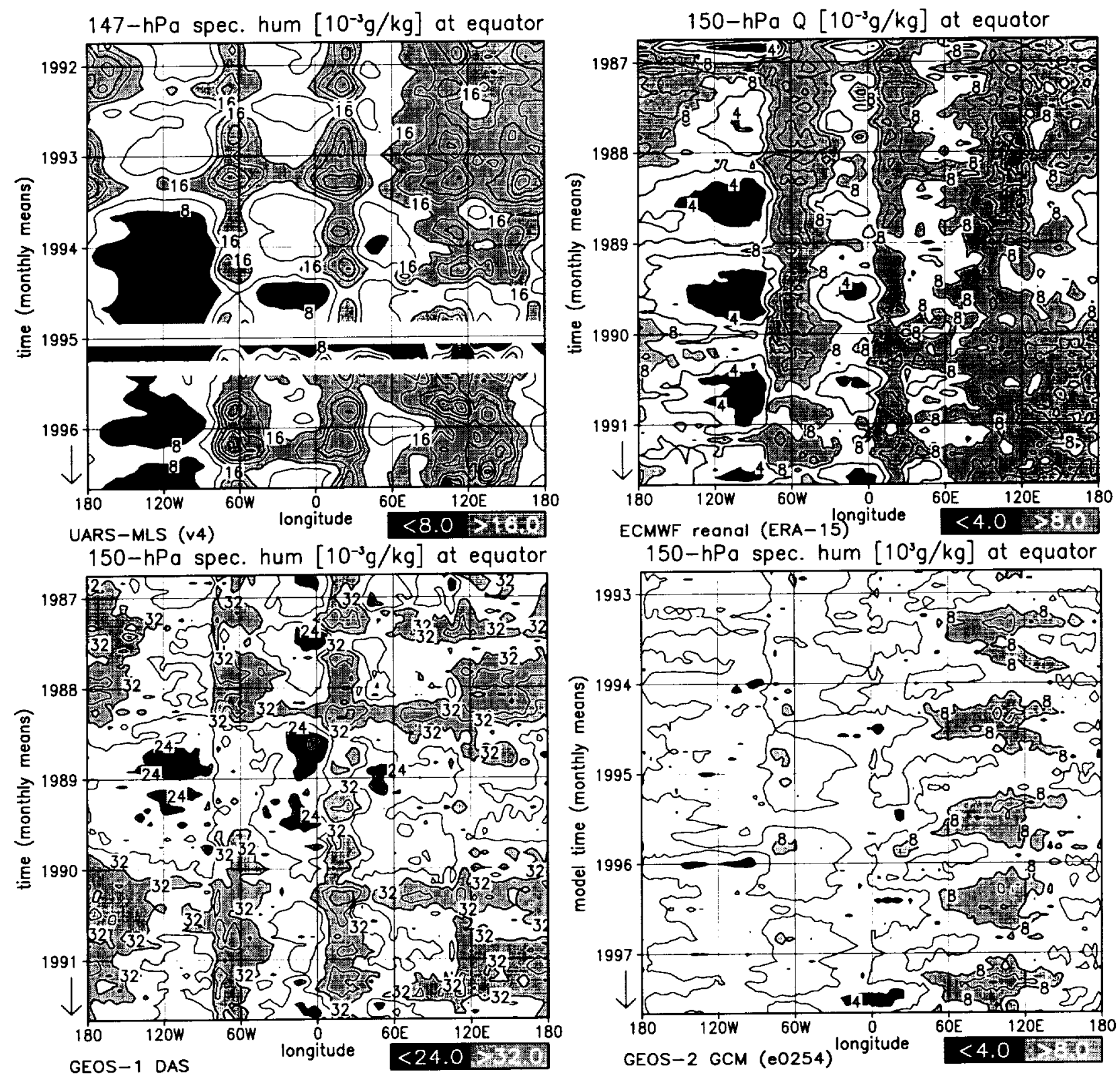

Fig. 3: Time series of the monthly averaged upper tropospheric specific humity $(\mathrm{g} / \mathrm{kg})$ at the equator. The longitudinal structure is shown for 5-year periods, beginning in October from four different sources. Top left: UARS-MLS (Read et al. 1999): $147 \mathrm{hPa}, 1991-1996$, contour interval $4 \times 10^{-3} \mathrm{~g} / \mathrm{kg},<8 />16$ shaded dark/light. top right: ECMWF reanalyses (Gibson et al., 1997): $150 \mathrm{hPa}, 1986-1991$, contour interval $2 \times 10^{-3} \mathrm{~g} / \mathrm{kg},<4 />8$ shaded dark $/$ light. bottom left: GEOS-1 DAS (Schubert et al., 1993): $150 \mathrm{hPa}, 1986-1991$, contour interval $8 \times 10^{-3} \mathrm{~g} / \mathrm{kg},<24 />32$ shaded dark/light. bottom right: GEOS-2 GCM: $150 \mathrm{hPa}$, model years $1992-1997$, contour interval $2 \times 10^{-3} \mathrm{~g} / \mathrm{kg}$, $<4 />8$ shaded dark/light. The UARS-MLS data were smoothed using a nine-point filter. Note that the shading and the contour interval differ between the panels; they were chosen to emphasize the dry and moist regions in each dataset at the expense of allowing absolute intercomparison of these vastly different datasets. 


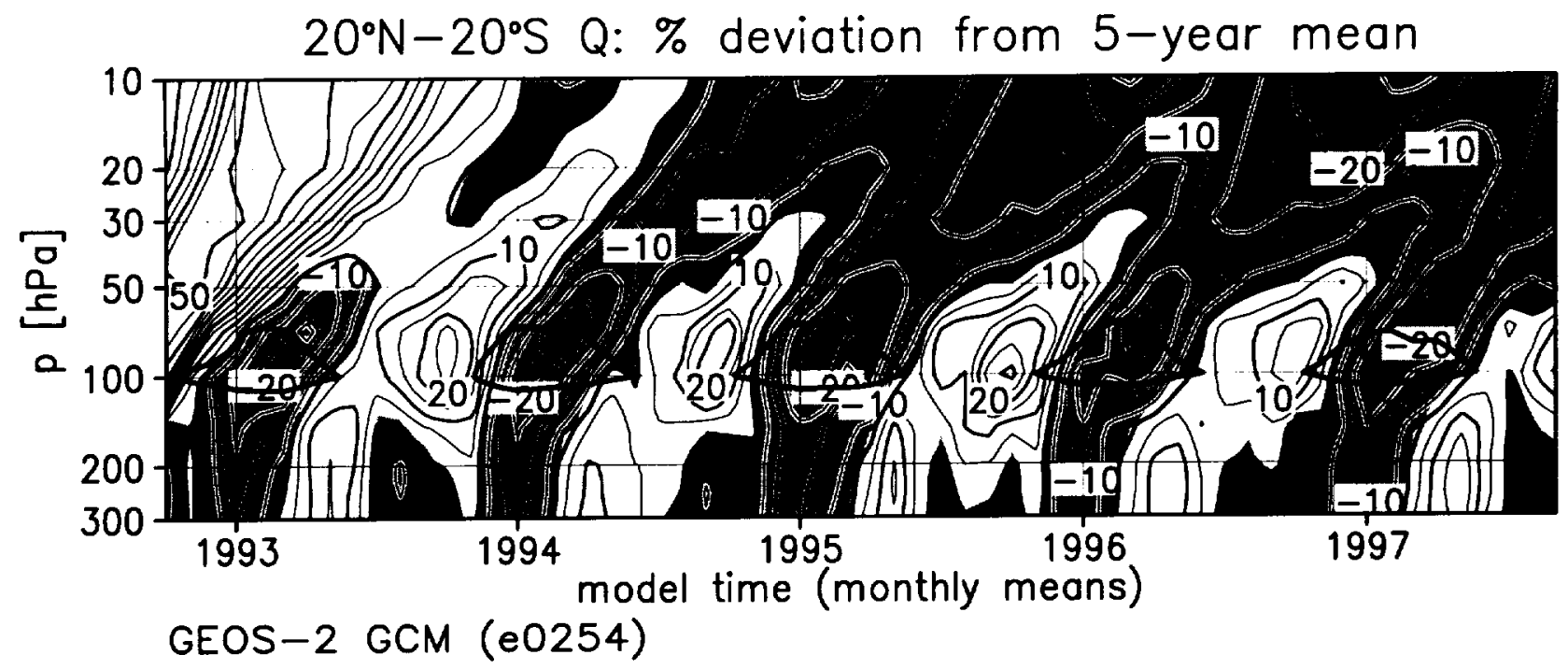

Fig. 4: Time series of the monthly averaged specific humidity anomalies relative to the 5-year mean averaged over $20^{\circ} \mathrm{N}$ to $20^{\circ} \mathrm{S}$ atmosphere in the GEOS-2 GCM. Dry anomalies are shaded and the contour interval is $5 \%$. Additionally, the $195 \mathrm{~K}$ contours are shown, illustrating the seasonal occurrence of extremely low temperatures near the tropical tropopause in northern winter.

DAS the wetness arises from the specification of the saturation specific humidities in the GEOS-1 GCM. Use of saturation with respect to a water surface leads to far too little condensation in the upper troposphere and, since there are few observations of upper tropospheric water vapor to constrain the assimilation system, the GCM estimates are not reduced by data insertion. This GCM formulation has been amended in the GEOS-2 GCM, and this leads to a much drier upper troposphere in this version than in the GEOS-1 GCM and DAS. The ECMWF reanalysis gives water vapor maxima in excess of $10-12 \mathrm{mg} / \mathrm{kg}$ at $150 \mathrm{hPa}$ in the wettest regions over the deep convective systems, with values lower than $4 \mathrm{mg} / \mathrm{kg}$ in the drier parts of the upper troposphere. Compared to all of these values, the GEOS-2 GCM has a dry bias in the upper troposphere, consistent with less water vapor being lifted by convection in the model atmosphere than in the ECMWF reanalyses. The lack of observational constraints means that the ECMWF values at $150 \mathrm{hPa}$ are also largely a GCM-derived feature (this is the lowest pressure at which humidity data are released in the reanalyzed product). The deduction that the GEOS-2 GCM is too dry in the upper troposphere is thus uncertain. Much better estimates of the real upper tropospheric moisture are needed for GCM validation and studies of the radiative forcing of the climate system by this important radiatively active gas.

The stratospheric water vapor budget is believed to be limited by the injection of dry air through the tropical tropopause and its slow transport through the middle atmosphere (Newell and Gould-Stewart, 1981), along with the chemical source of methane oxidation in the stratosphere. Photolysis in the mesosphere is also important when air is transported downwards in the polar regions. Since all middle atmospheric chemistry is neglected in the GEOS-2 GCM, there are two constraints on the stratospheric water vapor distributions. First, the upper tropospheric water vapor concentrations affect the amount available for input into the stratosphere. Second, the reality of the the vertical transport in the tropopuase region and the lower stratosphere determines the fluxes.

Mote et al. $(1996,1998)$ have examined the vertical transport of the conserved quanity $\dot{H}$ in the lower stratosphere, using UARS-HALOE data. $\tilde{H}$ is defined as the concentration of methane plus twice that of water vapor, since a "good approximation" (at the 10\%-level) to methane oxidation is the production of two water vapor modelcules. They show a slow, coherent vertical transport in the tropical lower stratosphere, corresponding to an ascent rate of $0.2 \mathrm{~mm} / \mathrm{s}$ near $20 \mathrm{~km}$. A qualitatively similar ascending motion can be seen in the GEOS-2 GCM water vapor (Fig. 4), which is shown relative to the long-term mean. The 
time serie's clearly show the passage of drier air from the tropopause region in northern winter and moister air in northern summer and the vertical transport of these anomalies through the lower stratosphere. The anomalies ascend about $30 \%$ faster than in the observations (Mote et al., 1998), indicating either too much advection or that the lower stratosphere of the model is too diffusive. This issue is now being examined more fully, along with an assessment of the transport mechanisms, which can be determined from the GCM because all transport terms can be determined in a consistent manner.

Figure 4 also reveals that the stratospheric water vapor is decreasing in the GEOS-2 GCM simulation. This is consistent with the advection of dry air through the tropical tropopause region, since in the middle atmosphere of the model there are no sources (or sinks) of water vapor. The model field was initialized with observations from SAGE and simply integrated forward in time. Currently, this predicted water wapor concentration is not used in the radiation scheme of the GCM; standard climatological values are used instead. A current focus of model development is the inclusion of methane and a consistent representation of the water vapor budget throughout the atmosphere. This should allow the modelled middle atmospheric water vapor to be used in the radiation scheme in a self-consistent manner. Furthermore, the availability of both methane and water vapor will facilitate full diagnosis of the transport characteristics of future GEOS GCMs and the DAS.

\section{SUMMARY AND DISCUSSION}

Some aspects of the climatology of the tropical atmosphere in the GEOS-2 GCM have been discussed. While the zonal-mean temperature in the tropopause region is well simulated, the zonal asymmetries are stronger than they appear in observational estimates. At and above the tropopause a range of interannual variability (associated with the QBO) is not captured by the GCM. The upper troposphere appears too dry in comparison with the most reliable independent estimates of the global distribution, a characteristic which may arise from the transport of water vapor from the middle troposphere or an excess of precipitation from the deep convection scheme; given that the middle troposphere is too moist, the latter may be the most likely explanation. Transport through the tropical tropopause is in good agreement with observational estimates, in that the dryest air enters the stratosphere when the tropopause temperatures are lowest in northern winter; however, the ascent within the tropical lower stratosphere is too rapid in the GCM. More quantitative studies of the water vapor budget of the GCM are currently underway. These include (i) studies of sensitivity to the transport scheme, with comparisons between the current fourth-order advection scheme and the flux-corrected semi-Lagrangian scheme of Lin and Rood (1996), and (ii) quantitative estimates of the cross-tropopause transport in the GCM (and the DAS) using local estimates of the vertical motion along with the specific humidity (on a daily basis).

\section{ACKNOWLEDGEMENTS}

We are grateful to everyone who has been involved in the development of the GEOS GCMs over the years, and to colleagues in the data assimilation office who have helped keep it running.

\section{REFERENCES}

Chou M.D., A solar radiation model for use in climate studies. J. Atmos. Sci., 49, 762-772 (1992).

Chou, M.-D., and M.J. Suarez, An efficient thermal infrared radiation parametrization for use in atmospheric general circulation models. NASA Tech. Mem. 104606, 3, 85pp (1994).

Data Assimilation Office (DAO), Algorithm Theoretical Basis Document for Goddard Earth Observing System Data Assimilation System (GEOS DAS) with a focus on version 2. (1996).

DeFries, R.S., and J.R.G. Townsend, NDVI-derived land cover classification at global scales. Int. J. Rem. Sens., 15, 3567-3586 (1994). 
Dormalu. D.I... and P..J. Sellers, A global climatology of albedo, roughness length and stomatal resistance for atmospheric general circulation models as represented by the Simple Biosphere Model (SiB) J. Appl. Meteorol., 28, 833-855 (1989).

Gibson J.K., P. Kăllberg, S. Uppala, A. Hernandez, A. Nomura, and E. Serrano, ECMWF re-analysis project report series, 1: ERA description. ECMWF, Reading, UK (1997).

Gates, W.L., AMIP: The atmospheric model intercomparison project. Bull. Am. Meteorol. Soc., 73, 1962$1970(1992)$.

Helfand, H.M., and J.C. Labraga, Design of a non-singular level 2.5 second-order closure model for the prediction of atmospheric turbulence. J. Atmos. Sci., 45, 113-132 (1988).

Helfand, H.M., and S.D. Schubert, Climatology of the Great Plains low-level jet and its contribution to the continental moisture budget of the United States. J. Clim., 8, 784-806 (1995).

Lin, S.-J., and R.B. Rood, Multi-dimensional flux-form semi-Lagrangian transport schemes. Mon. Weath. Rev., 124, 2046-2070 (1996).

Mote, P.W., K.H. Rosenlof, M.E. McIntyre, E.S. Carr, J.C. Gille, J.R. Holton, J.S. Kinnersley, H.C. Pumphrey, J.M. Russell III, and J.W. Waters, An atmospheric tape recorder: The imprint of tropical tropopause temperatures on stratospheric water vapor. J. Geophys. Res., 101, 3989-4006 (1996).

Mote, P.W., T.J. Dunkerton, M.E. McIntyre, E.A. Ray, P.H. Haynes, and J.M. Russell III, Vertical velocity, vertical diffusion, and dilution by midlatitude air in the tropical lower stratosphere. $J$. Geophys. Res., $103,8651-8666$ (1998).

Moorthi, S., and M.J. Suarez Relaxed Arakawa-Schubert: A parametrization of moist convection for general circulation models. Mon. Weath. Rev., 120, 978-1002 (1992).

Newell R.E., and S. Gould-Stewart, A stratospheric fountain? J. Atmos. Sci., 38, 2789-2796 (1981).

Pawson S., and M. Fiorino, A comparison of reanalyses in the tropical stratosphere. Part 1: Thermal structure and the annual cycle. Clim. Dyn., 14, 631-644 (1998a).

Pawson S., and M. Fiorino, A comparison of reanalyses in the tropical stratosphere. Part 2: The quasibiennial oscillation. Clim. Dyn., 14, 645-658 (1998b).

Read., W.L., J.W. Waters, D.A. Flower, L. Froidevaux, R.F. Jarnot, D.L. Hartmann, R.S. Harwood, and R.B. Rood, Upper-tropospheric water vapor from UARS MLS. Bull. Am. Meteorol. Soc., 76, 2381-2389 (1996).

Read W.L., et al., Upper Atmosphere Research Satellite-Microwave Limb Sounder upper tropospheric humidity validation. In preparation (1999).

Schemm, J., S. Schubert, J. Terry and S. Bloom, Estimates of monthly mean soil moisture for 1979-1989. NASA, Tech. Mem., 104571 (1992).

Sandor, B.J., W.L. Read, J.W. Waters, and K.H. Rosenlof, Seasonal behavior of tropical to midlatitude upper tropospheric water vapor from UARS MLS. J. Geophys. Res., 103, 25935-25947 (1998).

Schubert, S., J. Pfaentner, and R.B. Rood, An assimilated dataset for earth science applications. Bull. Am. Meteorol. Soc., 77, 437-471 (1993).

Takacs, L.L., and M.J. Suarez, Circulation Model - Version 1. NASA. Tech. Mem. 104606, Vol. 6, 97pp (1996).

Takacs, L.L., A. Molod, and T. Wang, Documentation of the Goddard Earth Observing System (GEOS) General Circulation Model - Version 1. NASA. Tech. Mem. 104606, Vol. 1, 97pp (1994). 